\title{
Development and Accuracy Evaluation of Augmented Reality-based Patient Positioning System in Radiotherapy: A Phantom Study
}

\author{
KAZUO TARUTANI ${ }^{1,2}$, HARUYUKI TAKAKI ${ }^{1}$, MASATAKA IGETA ${ }^{3}$, MASAYUKI FUJIWARA $^{1}$, \\ AYAKO OKAMURA ${ }^{2}$, FUTO HORIO ${ }^{4}$, YUKI TOUDOU ${ }^{2}$, SATOSHI NAKAJIMA ${ }^{2}$, \\ KAZUFUMI KAGAWA ${ }^{2}$, MASAO TANOOKA ${ }^{5}$ and KOICHIRO YAMAKADO ${ }^{1}$ \\ ${ }^{1}$ Department of Radiology, Hyogo College of Medicine, Hyogo, Japan; \\ ${ }^{2}$ Japan Organization of Occupational Health and Safety Kansai Rousai Hospital, Hyogo, Japan; \\ ${ }^{3}$ Department of Biostatistics, Hyogo College of Medicine, Hyogo, Japan; \\ ${ }^{4}$ Kobe Digital Labo Incorporated, Hyogo, Japan; \\ ${ }^{5}$ Department of Radiotherapy, Takarazuka City Hospital, Hyogo, Japan
}

\begin{abstract}
Background/Aim: To develop and evaluate the accuracy of augmented reality (AR)-based patient positioning systems in radiotherapy. Materials and Methods: $A R$ head-mounted displays (AR-HMDs), which virtually superimpose a three-dimensional (3D) image generated by the digital imaging and communications in medicine (DICOM) data, have been developed. The AR-based positioning feasibility was evaluated. Then, the setup errors of three translational axes directions and rotation angles between the AR and the conventional laser-based positioning were compared. Results: The AR-based pelvic phantom positioning was feasible. The setup errors of AR-based positioning were comparable to laser-based positioning in all translational axis directions and rotation angles. The time necessary for AR-based positioning was significantly longer than that for laser-based positioning (171.0 s vs. $47.5 \mathrm{~s}$, p<0.001). Conclusion: AR-based positioning for radiotherapy was feasible, and showed comparable positioning errors to those of conventional line-based positioning; however, a markedly longer setup time was necessary.
\end{abstract}

This article is freely accessible online.

Correspondence to: Haruyuki Takaki, MD, Ph.D., Department of Radiology, Hyogo College of Medicine, 1-1, Mukogawa-cho, Nishinomiya, Hyogo, 663-8501, Japan. Tel: +81 669451181, Fax: +81669451900, e-mail: takakiharuyuki@gmail.com

Key Words: Augmented reality, head mounted display system, image-guided radiotherapy, patient setup.
Recently, demand for radiotherapy has increased to meet the needs of the growing number of cancer patients (1-4). To perform accurate radiotherapy, accurate and reproducible patient positioning on the couch of a linear accelerator (LINAC) is fundamentally important. Traditionally, patient positioning for radiotherapy has been performed by positioning laser and alignment markers drawn on a patient's skin (5-7). For image-guided radiotherapy (IGRT), patient positioning is performed using cone-beam computed tomography (CBCT) and planar kilovolt $(\mathrm{kV})$ images. However, alignment markers drawn on the patient body surface are still necessary for body position adjustment. Such patient positioning methods have some limitations. Cosmetic issues caused by alignment markers represent one limitation. Moreover, alignment markers must be maintained during the treatment period, leading to deterioration of the patient's quality of life (8-10).

Augmented reality (AR), a variant of virtual reality (VR), enhances real-world imaging by virtually superimposing computer-generated images (11-14). If AR is applied to the patient position at the time of radiotherapy, then it might become possible to skip line drawing on the patient's body.

For this study, an AR-based patient positioning system was developed using a commercially available software and a wearable device. In addition, the accuracy of patient positioning using the AR-based patient positioning system was confirmed by comparison with conventional laser-based positioning.

\section{Materials and Methods}

This study, because it involved a phantom experiment, did not require the approval of an institutional review board (IRB). 

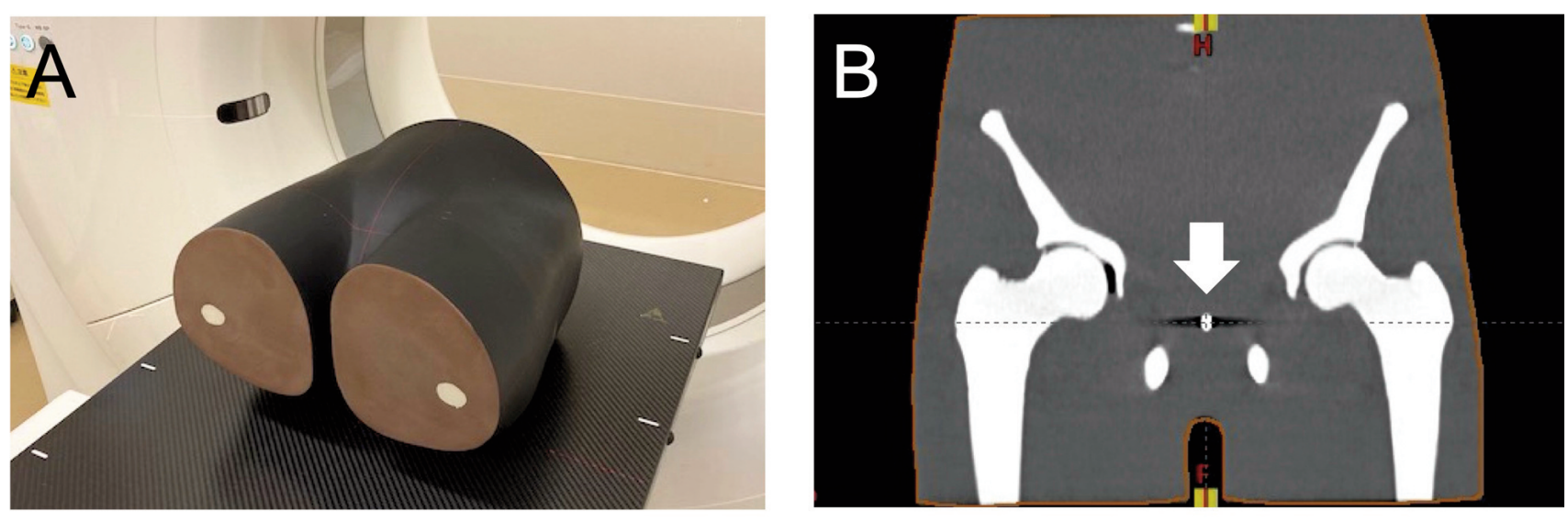

Figure 1. Pelvic phantom. A) appearance of the pelvic phantom; B) coronal CT image of the pelvic phantom. An iron ball is embedded in the phantom (white arrow).

For this study, the AR head-mounted display (AR-HMD) system, which superimposes a three-dimensional (3D)-image generated using digital imaging and communications in medicine (DICOM) data was developed to enable positioning without drawing of alignment markers. Then, the setup errors of the developed AR-based positioning were compared using the AR-HMD system and conventional laser-based positioning. All experiments were performed using a pelvic phantom (BrainLab pelvis phantom; BrainLab Medical Systems, Westchester, IL, USA) that includes an iron ball (Figure 1). This iron ball was used as an isocenter for this study.

Development of the AR-HMD system. The AR-HMD system development process consists of the following five steps as presented in Figure 2. First, DICOM data of the CT imaging of pelvic phantom were acquired using a CT scanner (SOMATOM Definition AS; Siemens Healthineers, Forchheim, Germany) (Step 1). Second, DICOM data of the pelvic phantom CT images were transferred to the image workstation (Ziostation2; Ziosoft Inc., Tokyo, Japan) to generate 3D images of the surface structure and iron ball of the pelvic phantom (Step 2). The created 3D-CT DICOM data were converted to the OBJ file format and imported to the game development engine software (Unity; Unity Technologies, San Francisco, CA, USA). Using this software, the color, size, and transparency of the $3 \mathrm{D}$ pelvic phantom image were adjusted (Figure 3A). In addition, three virtual lasers ( $\mathrm{x}, \mathrm{y}$, and $\mathrm{z}$ axis) were added at the isocenter (i.e., position of the iron marker) of the 3D pelvic phantom image (Figure 3A). This virtual laser was used at the time of positioning of the pelvic phantom on the LINAC couch with a six-axis drive (TrueBeam; Varian Medical System, Palo Alto, CA, USA), as described in a later section.

Next, an application that enables the position adjustment of a 3D phantom image was created using game development engine software (Unity) and tool kit software (Mixed Reality ToolKit; Microsoft Corp., Redmond, WA, USA) (Step 3). This position adjustment application includes two functions: a hand tracking function that can track hand movements and which can manipulate the 3D phantom image position and a dedicated control panel function that enables fine adjustment of the $3 \mathrm{D}$ phantom image position (Figure 3A).

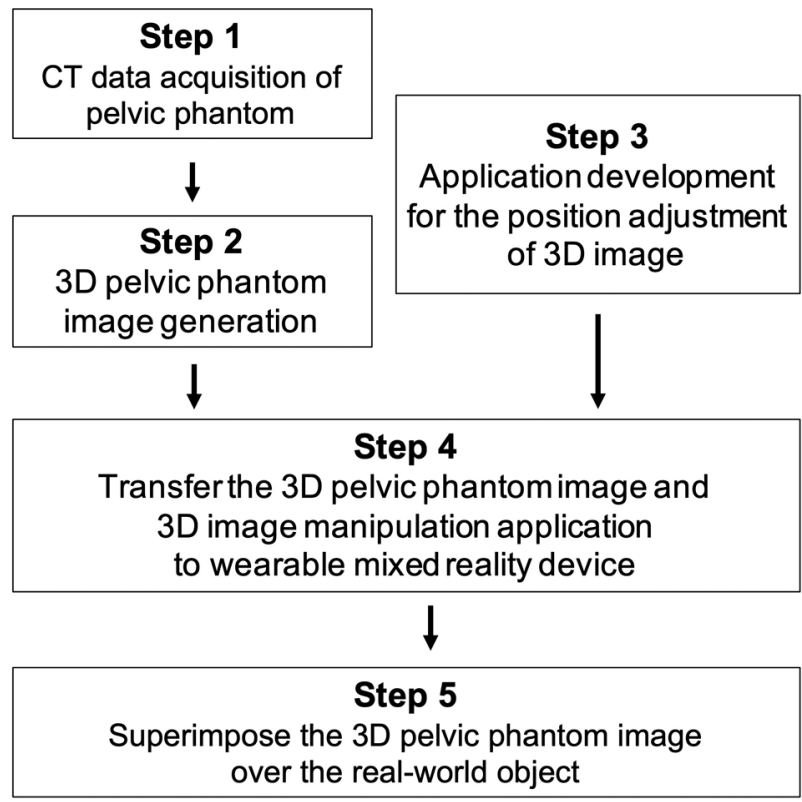

Figure 2. Flowchart of augmented reality head-mounted display system development. CT data of the pelvic phantom were acquired (Step 1). CT data were transferred to the image workstation; a $3 D$ pelvic phantom image with virtual lasers was created (Step 2). Applications that enable the position adjustment of $3 D$ images were developed (Step 3). Both the $3 D$ pelvic phantom image and the position adjustment application were incorporated and transferred to a wearable mixed reality device (Step 4). Holograms of $3 D$ pelvic phantom image and real-world objects are displayed simultaneously on the wearable mixed reality device (Step 5).

Then, in step 4, both the 3D pelvic phantom image generated in step 2 and the position adjustment application developed in step 3 were incorporated into an executable file using the integrated application development environment (Microsoft Visual Studio; Microsoft Corp.). The application was transferred to a wearable 

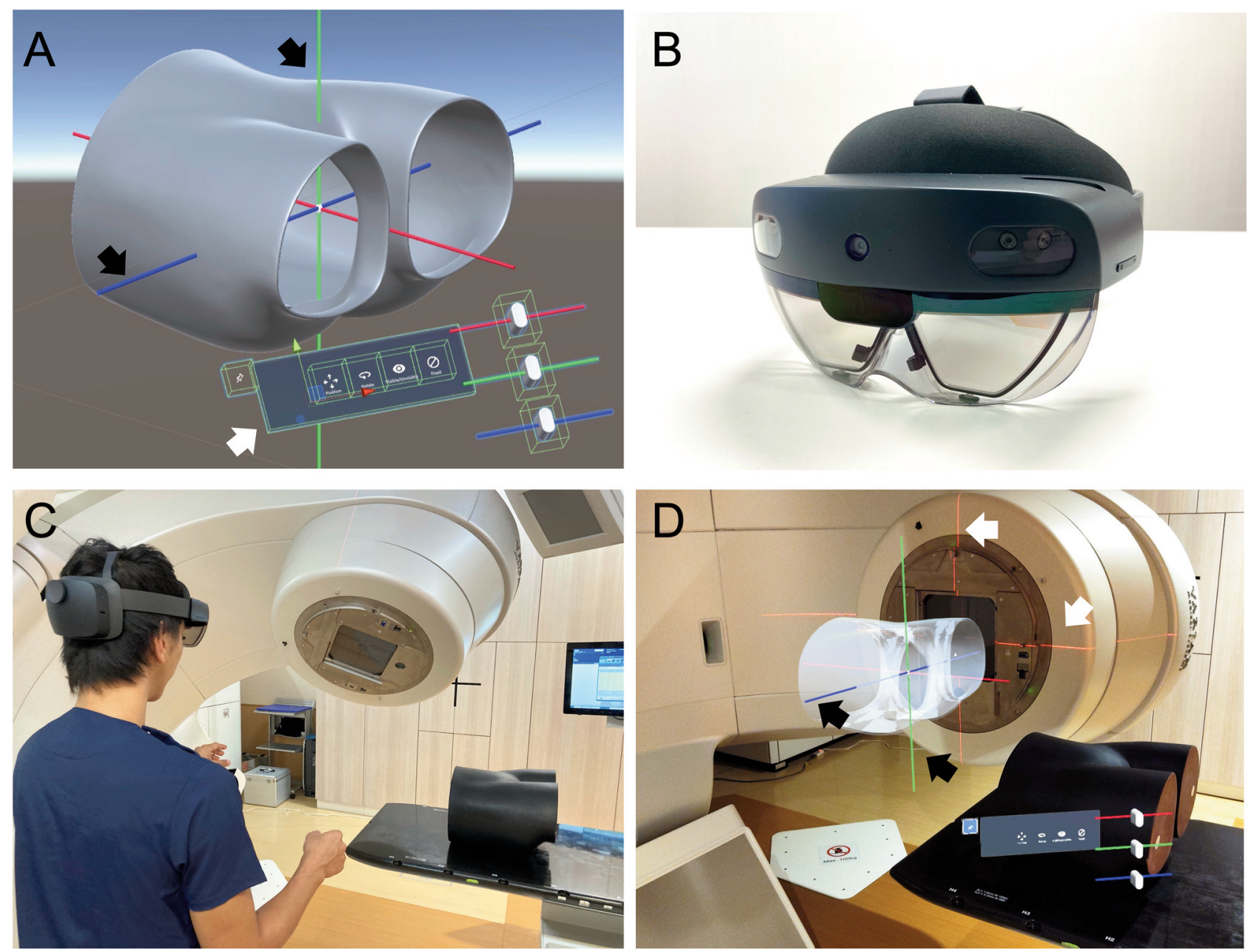

Figure 3. Augmented reality head-mounted display system. A: 3D pelvic phantom image and virtual laser image (black arrow). The control panel (white arrow) can be operated by pressing a switch in virtual space. By operating the slide bar on the right side, an interface that can move in the translation direction and which can rotate from the central axis has been developed. The position of the $3 D$ pelvic phantom image can be finetuned. B: Wearable mixed-reality device (HoloLens 2). C: Actual operation scenery. D: Three virtual laser and $3 D$ pelvic phantom images visible through a wearable mixed reality device.

mixed reality device (HoloLens 2; Microsoft Corp.) (Figure 3B). Finally, both the hologram of the $3 \mathrm{D}$ pelvic phantom image and real-world objects were displayed simultaneously on the wearable mixed reality device (Step 5) (Figure 3C and 3D).

AR-based and laser-based positioning. After AR-HMD system development, the feasibility of positioning the pelvic phantom on the LINAC couch using the AR-HMD system (AR-based positioning) was evaluated. Subsequently, conventional laser-based positioning was also performed. Their setup errors and setup times were compared. Workflows of AR-based and laser-based positioning methods are portrayed in Figure 4.

In AR-based positioning, an operator wore the AR-HMD system, which displays both the 3D pelvic phantom image and three virtual lasers (Figure 3C). Then, using the hand tracking function and the dedicated control panel function, the location of the virtual isocenter of the $3 \mathrm{D}$ phantom image was adjusted at the location of the mechanical isocenter of LINAC indicated by the positioning lasers (Figure 3D and $4 \mathrm{~A})$. Here, three virtual lasers were used as a guide to adjust the $3 \mathrm{D}$ phantom image virtual isocenter location and the mechanical isocenter of LINAC. After adjustment of the 3D phantom image, the real pelvic phantom was set on the LINAC couch so that the 3D phantom image and the real pelvic phantom were completely overlapping using the ARHMD system (Figure 4A). In AR-based positioning, alignment markers were not drawn on the surface of the real pelvic phantom.

Using laser-based positioning, pelvic phantoms were created with three surface alignment markers respectively showing the $x, y$, and $\mathrm{z}$ axis of the isocenter (Figure 4B). Using the alignment marker of the pelvic phantom and the positioning lasers of LINAC, the respective isocenter locations were adjusted. 


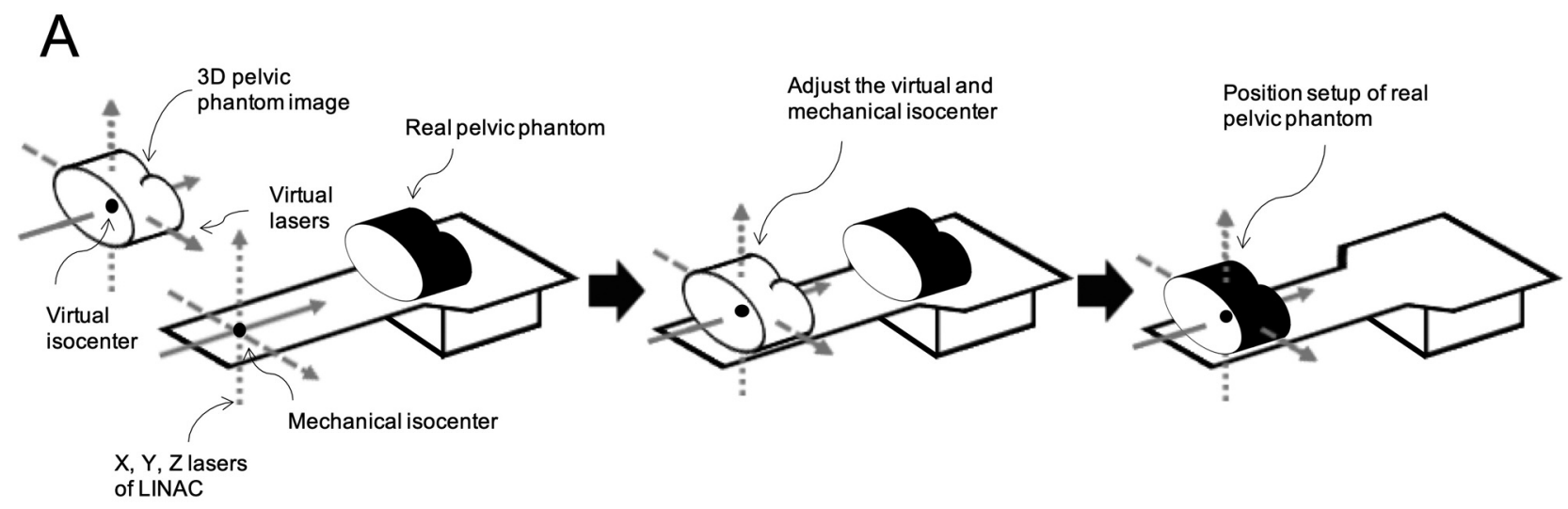

B

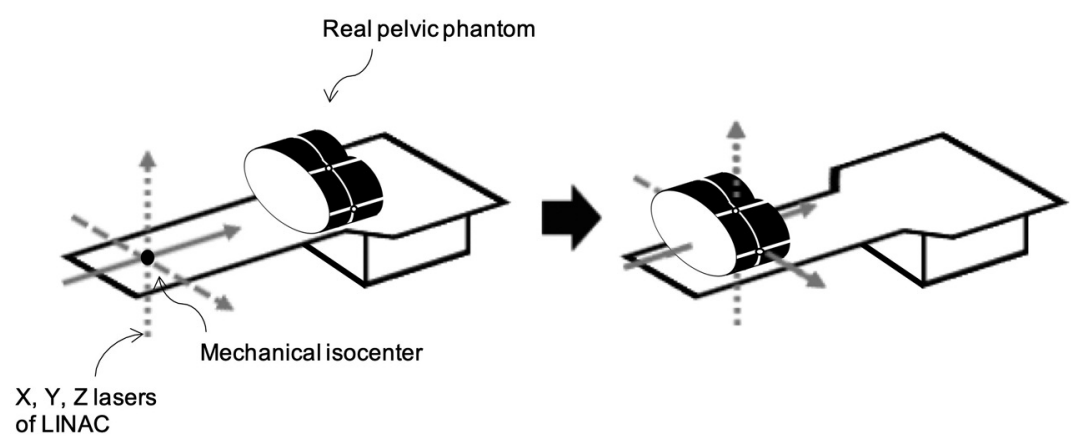

Figure 4. Overview of augmented reality (AR) and laser-based positioning. A) AR-based positioning. Using the hand-tracking function and the dedicated control panel function, the $3 D$ phantom image virtual isocenter location was adjusted at the location of the mechanical isocenter of LINAC, as indicated by positioning lasers. After adjustment of the $3 D$ phantom image, a real pelvic phantom was set on the couch of LINAC so that the 3D phantom image and the real pelvic phantom were completely overlapped by the AR-HMD system. B) Laser-based positioning. Using the alignment marker of pelvic phantom and the positioning lasers of LINAC, the respective isocenter locations were adjusted.

Assessments. Three radiation therapy technologists, respectively with 22,17 , and 13 years of experience in radiotherapy, performed AR-based positioning 10 times each (total 30 times). The feasibility was evaluated based on their evaluations. Feasibility of AR-based positioning was defined as successful placement of the pelvic phantom on the couch of LINAC using the AR-HMD system. Subsequently, conventional laser-based positioning was also performed by the same radiological technologist 10 times each. Setup errors between the AR-based and laser-based positioning were compared. For this study, the setup error was defined as the difference between the pre-planned phantom position and the actual phantom position set by AR-based or laser-based positioning. Three translational errors (i.e., vertical, longitudinal, and lateral) and three rotational errors (i.e., pitch, roll, and yaw) were evaluated as setup errors. The errors of each setup were measured using image registration software (Varian Offline Review software; Varian Medical System, Palo Alto, CA, USA). The time necessary for each positioning method was also measured.

Statistical analysis. The setup errors of AR-based and laser-based positioning were analyzed using a linear mixed-effects model for repeated measures (15). For each of the setup error and time measurements, the least squares (LS) means and 95\% confidence interval (CI) were calculated for each group based on the mixedeffects model. The LS mean difference between AR-based and laserbased positioning for each of the measurements and its 95\% CI were calculated. Contrast tests for LS mean differences were also performed. The confidence intervals and $p$-values were calculated based on the sandwich-type robust standard error. A two-sided $p$ value of less than 0.05 was regarded as statistically significant without adjustment for multiplicity. All statistical analyses were conducted using SAS software (SAS Institute Inc., Cary, NC, USA).

\section{Results}

Feasibility. The pelvic phantom was placed on the couch of LINAC in all AR-based positionings. Therefore, the feasibility of AR-based positioning was 100\% (30/30).

Setup error. The LS means of the translational errors in ARbased and laser-based positioning were $-0.82 \mathrm{~mm}$ 

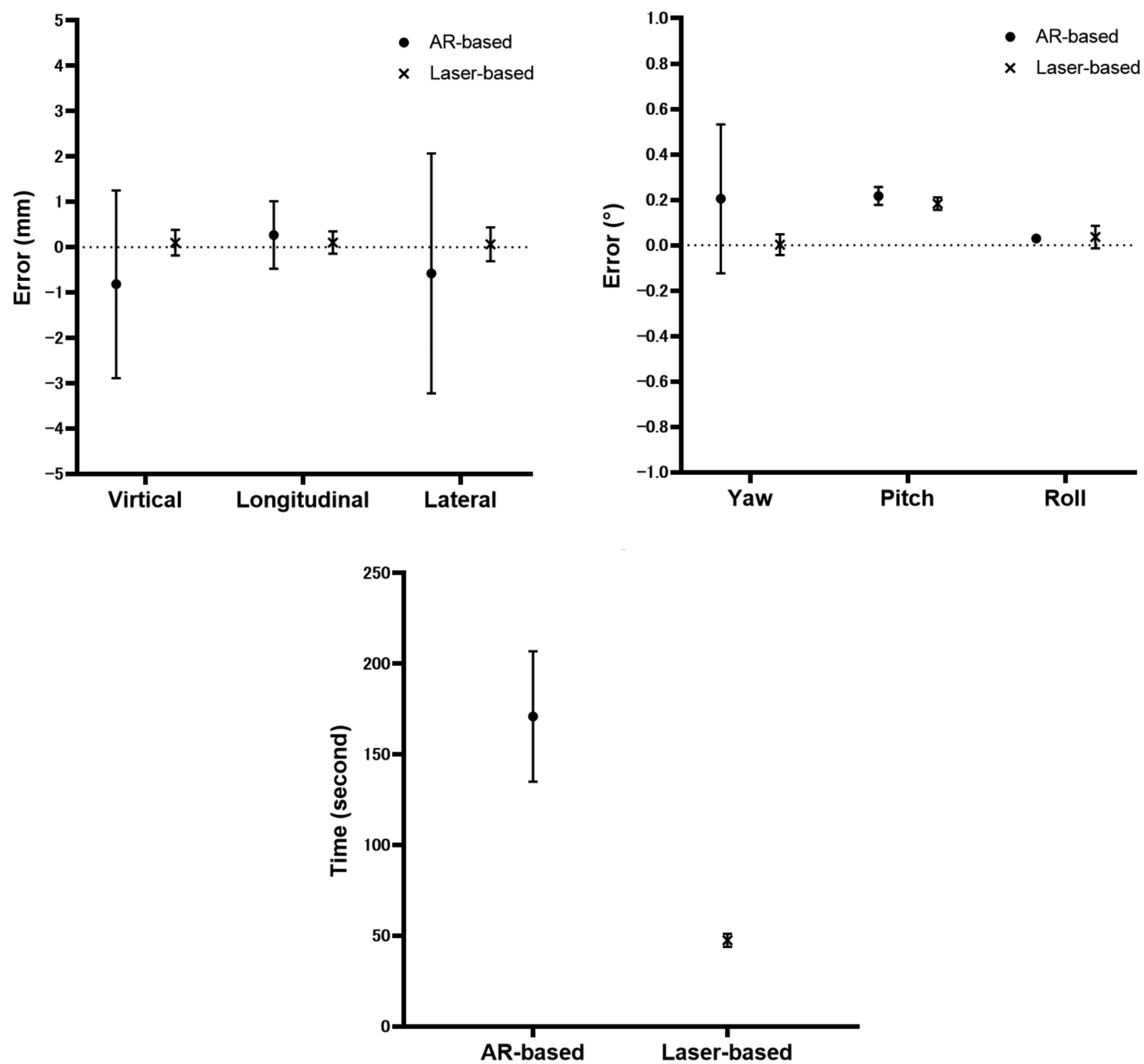

Figure 5. Least square (LS) means and 95\% confidence interval (CI) for augmented reality (AR)-based and laser-based positioning errors and setup times. A) Translational error. The LS means of the translational errors in AR-based and laser-based positioning were $-0.82 \mathrm{~mm}(95 \% \mathrm{CI}=-2.89$ $1.25 \mathrm{~mm})$ and $0.10 \mathrm{~mm}(95 \% \mathrm{CI}=-0.18-0.38 \mathrm{~mm})$ on the vertical axis, $0.27 \mathrm{~mm}(95 \% \mathrm{CI}=-0.47-1.01 \mathrm{~mm})$ and $0.10 \mathrm{~mm}(95 \% \mathrm{CI}=-0.14-0.35 \mathrm{~mm})$ on the longitudinal axis, and $-0.58 \mathrm{~mm}(95 \% \mathrm{CI}=-3.22-2.07 \mathrm{~mm})$ and $0.07 \mathrm{~mm}(95 \% \mathrm{CI}=-0.31-0.44 \mathrm{~mm})$ on the lateral axis, respectively. B) Rotational error. The LS means of the rotational errors in AR-based and laser-based positioning were $0.21^{\circ}\left(95 \% C I=-0.12-0.53^{\circ}\right)$ and $0.00^{\circ}$ $\left(95 \% C I=-0.04-0.05^{\circ}\right)$ in yaw, $0.22^{\circ}\left(95 \% C I=0.18-0.26^{\circ}\right)$ and $0.18^{\circ}\left(95 \% C I=0.16-0.21^{\circ}\right)$ in pitch, and $0.03^{\circ}\left(95 \% C I=0.02-0.04^{\circ}\right)$ and $0.04^{\circ}$ (95\%CI=-0.01-0.09) in roll. C) Setup time. The LS means of the setup time in AR-based and laser-based positioning were $171.0 \mathrm{~s}(95 \% \mathrm{CI}=135-$ $206.9 \mathrm{~s})$ and $47.5 \mathrm{~s}(95 \% \mathrm{CI}=43.9-51.2 \mathrm{~s})$.

$(95 \% \mathrm{CI}=-2.89-1.25 \mathrm{~mm})$ and $0.10 \mathrm{~mm}(95 \% \mathrm{CI}=-0.18-0.38$ $\mathrm{mm})$ on the vertical axis, $0.27 \mathrm{~mm}(95 \% \mathrm{CI}=-0.47-1.01 \mathrm{~mm})$ and $0.10 \mathrm{~mm}(95 \% \mathrm{CI}=-0.14-0.35 \mathrm{~mm})$ on the longitudinal axis, and $-0.58 \mathrm{~mm}(95 \% \mathrm{CI}=-3.22-2.07 \mathrm{~mm})$ and $0.07 \mathrm{~mm}$ $(95 \% \mathrm{CI}=-0.31-0.44 \mathrm{~mm})$ on the lateral axis (Figure $5 \mathrm{~A})$. The
LS mean differences between AR-based and laser-based positioning for the vertical, longitudinal, and lateral axis were, respectively, $-0.92 \mathrm{~mm}(95 \% \mathrm{CI}=-3.23-1.40 \mathrm{~mm})$ $(p=0.333), 0.17 \mathrm{~mm}(95 \% \mathrm{CI}=-0.57-0.90 \mathrm{~mm})(p=0.562)$, and $-0.64 \mathrm{~mm}(95 \% \mathrm{CI}=-3.50-2.22 \mathrm{~mm})(p=0.566)$. 
The LS means of the rotational errors in AR-based and laserbased positioning were $0.21^{\circ}\left(95 \% \mathrm{CI}=-0.12-0.53^{\circ}\right)$ and $0.00^{\circ}$ $\left(95 \% \mathrm{CI}=-0.04-0.05^{\circ}\right)$ for yaw, $0.22^{\circ}\left(95 \% \mathrm{CI}=0.18-0.26^{\circ}\right)$ and $0.18^{\circ}\left(95 \% \mathrm{CI}=0.16-0.21^{\circ}\right)$ for pitch, and $0.03^{\circ}(95 \% \mathrm{CI}=0.02-$ $\left.0.04^{\circ}\right)$ and $0.04^{\circ}(95 \% \mathrm{CI}=-0.01-0.09)$ for roll (Figure 5B). The LS mean differences between AR-based and laser-based positioning for yaw, pitch, and roll were, respectively, $0.20^{\circ}$ $\left(95 \% \mathrm{CI}=-0.10-0.50^{\circ}\right)(p=0.136), 0.03^{\circ}\left(95 \% \mathrm{CI}=-0.03-0.10^{\circ}\right)$ $(p=0.231)$, and $-0.01^{\circ}\left(95 \% \mathrm{CI}=-0.06-0.05^{\circ}\right)(p=0.744)$.

Setup time. The LS means of the setup time in AR-based and laser-based positioning were, respectively, $171.0 \mathrm{~s}(95 \% \mathrm{CI}=135$ $206.9 \mathrm{~s})$ and $47.5 \mathrm{~s}(95 \% \mathrm{CI}=43.9-51.2 \mathrm{~s})$ (Figure 5C). The LS mean difference between AR-based and laser-based positioning was $123.4 \mathrm{~s}$ (95\%CI=88.7-158.2 s). Significant difference was found between the time necessary for the AR-based and laserbased setup ( $p=0.001)$. Results show that AR-based setup requires more setup time than laser-based setup.

\section{Discussion}

Conventional line-based patient positioning, which uses alignment markers drawn on the patient's body surface, is useful for accurate and reproducible patient positioning during radiotherapy. However, such alignment markers induce cosmetic difficulties and degrade the patients' quality of life. Therefore, a positioning method that requires no drawing of surface alignment markers has been warranted.

Results of this study demonstrated that the newly developed AR-HMD system enabled performance of positioning for radiotherapy without drawing alignment markers on the surface. Moreover, translational and rotation errors between AR-based and laser-based systems were comparable in this phantom experiment. A tendency remained by which positioning errors in the AR-based positioning were greater than those of line-based positioning. This tendency might be attributable to the difference in the number of position adjustments between AR-based and linebased positioning. For line-based positioning, position adjustment was necessary only once: for position adjustment of the alignment marker on the pelvic phantom and for positioning of lasers of LINAC. However, for AR-based positioning, position adjustment was necessary twice: once for adjustment between the virtual and mechanical isocenter and once for adjustment between the 3D virtual phantom and real pelvic phantom. Another possible explanation for the larger positioning errors in the AR-based positioning is the technical limitations in the hologram stability of the ARHMD system used for this study (16-18). Vassallo et al. reported the displacement error of the HoloLens 2 as $5.83 \pm 0.51 \mathrm{~mm}(19)$.

The setup time necessary for AR-based positioning was significantly longer than that for laser-based positioning. A possible reason for this finding is the difference in the number of position adjustments between AR-based and linebased positioning. Additional position adjustment in ARbased positioning might lead to the longer setup time.

Although AR-based positioning required considerably more setup time and although it showed a tendency to have larger setup error, these drawbacks can be overcome through further development. For example, if a software that automatically adjusts the virtual and mechanical isocenter was developed, then it would be possible to reduce the position adjustment error and setup time. An improvement of the holographic software in regards to hologram stability is also expected to be helpful to increase the AR-based positioning accuracy.

This study includes several limitations. As an experimental phantom study performed using only a pelvic phantom, this study cannot provide results that are directly applicable to clinical practice. Further study conducted with phantoms of other types as well as in vivo experiments must be conducted to evaluate the utility of AR-based positioning. The small sample size examined in this study is another major limitation.

Despite these limitations, results obtained through this study suggest that the AR-HMD system is useful for positioning for radiotherapy without drawing alignment markers on the surface. Results of this study also provide useful information to increase the positioning accuracy and to shorten the setup time of ARbased positioning for radiotherapy.

\section{Conclusion}

AR-based positioning for radiotherapy was demonstrated as feasible in this phantom study. AR-based positioning showed comparable positioning error to that of conventional linebased positioning, although significantly longer setup time was necessary.

\section{Conflicts of Interest}

No actual or potential conflicts of interest exist in relation to this study.

\section{Authors' Contributions}

KT conceived the study, collected and analysed the data, and contributed to writing the manuscript. HT was responsible for the study conception and design, and conducted the study and drafting of the article. AO, FH, YT, SN performed the experiments. MI analysed the data. MF, KK, MT revised the article. HT, KY administrated and supervised the study. All Authors read and approved the final manuscript.

\section{Acknowledgements}

This research was conducted with the support of Hyogo College of Medicine, Hyogo, Japan and the support of research funding to promote the hospital function of the Japan Industrial Safety and Health Organization. 


\section{References}

1 Global Burden of Disease Cancer Collaboration, Fitzmaurice C, Akinyemiju TF, Al Lami FH, Alam T, Alizadeh-Navaei R, Allen C, Alsharif U, Alvis-Guzman N, Amini E, Anderson BO, Aremu O, Artaman A, Asgedom SW, Assadi R, Atey TM, Avila-Burgos L, Awasthi A, Ba Saleem HO, Barac A, Bennett JR, Bensenor IM, Bhakta N, Brenner H, Cahuana-Hurtado L, Castañeda-Orjuela CA, Catalá-López F, Choi JJ, Christopher DJ, Chung SC, Curado MP, Dandona L, Dandona R, das Neves J, Dey S, Dharmaratne SD, Doku DT, Driscoll TR, Dubey M, Ebrahimi H, Edessa D, El-Khatib Z, Endries AY, Fischer F, Force LM, Foreman KJ, Gebrehiwot SW, Gopalani SV, Grosso G, Gupta R, Gyawali B, Hamadeh RR, Hamidi S, Harvey J, Hassen HY, Hay RJ, Hay SI, Heibati B, Hiluf MK, Horita N, Hosgood HD, Ilesanmi OS, Innos K, Islami F, Jakovljevic MB, Johnson SC, Jonas JB, Kasaeian A, Kassa TD, Khader YS, Khan EA, Khan G, Khang YH, Khosravi MH, Khubchandani J, Kopec JA, Kumar GA, Kutz M, Lad DP, Lafranconi A, Lan Q, Legesse Y, Leigh J, Linn S, Lunevicius R, Majeed A, Malekzadeh R, Malta DC, Mantovani LG, McMahon BJ, Meier T, Melaku YA, Melku M, Memiah P, Mendoza W, Meretoja TJ, Mezgebe HB, Miller TR, Mohammed S, Mokdad AH, Moosazadeh M, Moraga P, Mousavi SM, Nangia V, Nguyen CT, Nong VM, Ogbo FA, Olagunju AT, Pa M, Park EK, Patel T, Pereira DM, Pishgar F, Postma MJ, Pourmalek F, Qorbani M, Rafay A, Rawaf S, Rawaf DL, Roshandel G, Safiri S, Salimzadeh H, Sanabria JR, Santric Milicevic MM, Sartorius B, Satpathy M, Sepanlou SG, Shackelford KA, Shaikh MA, Sharif-Alhoseini M, She J, Shin MJ, Shiue I, Shrime MG, Sinke AH, Sisay M, Sligar A, Sufiyan MB, Sykes BL, TabarésSeisdedos R, Tessema GA, Topor-Madry R, Tran TT, Tran BX, Ukwaja KN, Vlassov VV, Vollset SE, Weiderpass E, Williams HC Yimer NB, Yonemoto N, Younis MZ, Murray CJL and Naghavi M: Global, regional, and national cancer incidence, mortality, years of life lost, years lived with disability, and disability-adjusted life-years for 29 cancer groups, 1990 to 2016: A systematic analysis for the Global Burden of Disease study. JAMA Oncol 4(11): 1553-1568, 2018. PMID: 29860482. DOI: 10.1001/jamaoncol.2018.2706

2 Verellen D, De Ridder M and Storme G: A (short) history of image-guided radiotherapy. Radiother Oncol 86(1): 4-13, 2008. PMID: 18083259. DOI: 10.1016/j.radonc.2007.11.023

3 Jaffray DA: Image-guided radiotherapy: from current concept to future perspectives. Nat Rev Clin Oncol 9(12): 688-699, 2012. PMID: 23165124. DOI: 10.1038/nrclinonc.2012.194

4 Zelefsky MJ, Kollmeier M, Cox B, Fidaleo A, Sperling D, Pei X, Carver B, Coleman J, Lovelock M and Hunt M: Improved clinical outcomes with high-dose image guided radiotherapy compared with non-IGRT for the treatment of clinically localized prostate cancer. Int J Radiat Oncol Biol Phys 84(1): 125-129, 2012. PMID: 22330997. DOI: 10.1016/j.ijrobp.2011.11.047

5 Jimenez RB, Batin E, Giantsoudi D, Hazeltine W, Bertolino K, Ho AY, MacDonald SM, Taghian AG and Gierga DP: Tattoo free setup for partial breast irradiation: A feasibility study. J Appl Clin Med Phys 20(4): 45-50, 2019. PMID: 30945803. DOI: $10.1002 / \mathrm{acm} 2.12557$

6 Stanley DN, McConnell KA, Kirby N, Gutiérrez AN, Papanikolaou $\mathrm{N}$ and Rasmussen K: Comparison of initial patient setup accuracy between surface imaging and three point localization: A retrospective analysis. J Appl Clin Med Phys 18(6): 58-61, 2017. PMID: 28901684. DOI: 10.1002/acm2.12183
7 Landeg SJ, Kirby AM, Lee SF, Bartlett F, Titmarsh K, Donovan E, Griffin CL, Gothard L, Locke I and McNair HA: A randomized control trial evaluating fluorescent ink versus dark ink tattoos for breast radiotherapy. Br J Radiol 89(1068): 20160288, 2016. PMID: 27710100. DOI: 10.1259/bjr.20160288

8 Clow B and Allen J: Psychosocial impacts of radiation tattooing for breast cancer patients: a critical review. Can Womens Stud 28: 46-52, 2010.

9 Fingeret MC, Teo I and Epner DE: Managing body image difficulties of adult cancer patients: lessons from available research. Cancer 120(5): 633-641, 2014. PMID: 24895287. DOI: 10.1002/cncr.28469

10 Sewak S, Graham P and Nankervis J: Tattoo allergy in patients receiving adjuvant radiotherapy for breast cancer. Australas Radiol 43(4): 558-561, 1999. PMID: 10901983. DOI: 10.1046/j.1440-1673.1999.00733.x

11 Heinrich F, Schwenderling L, Becker M, Skalej M and Hansen C: HoloInjection: augmented reality support for CT-guided spinal needle injections. Healthc Technol Lett 6(6): 165-171, 2019. PMID: 32038851. DOI: 10.1049/htl.2019.0062

12 Amini S and Kersten-Oertel M: Augmented reality mastectomy surgical planning prototype using the HoloLens template for healthcare technology letters. Healthc Technol Lett 6(6): 261265, 2019. PMID: 32038868. DOI: 10.1049/htl.2019.0091

13 Golse N, Petit A, Lewin M, Vibert E and Cotin S: Augmented reality during open liver surgery using a markerless non-rigid registration system. J Gastrointest Surg 25(3): 662-671, 2021. PMID: 32040812. DOI: 10.1007/s11605-020-04519-4

14 Fredrickson VL, Lin M, Catapano JS and Attenello FJ: Commentary: Clinical accuracy of holographic navigation using point-based registration on augmented-reality glasses. Oper Neurosurg (Hagerstown) 17(6): E229-E230, 2019. PMID: 31515566. DOI: $10.1093 /$ ons/opz266

15 West BT, Welch KB and Galecki AT: Models for RepeatedMeasures Data: The Rat Brain Example. In: Linear mixed models: a practical guide using statistical software. West BT, Welch KB, Galecki AT (eds.). Second ed. Boca Raton, Chapman and Hall/CRC, pp. 206-207, 2014.

16 Kuhlemann I, Kleemann M, Jauer P, Schweikard A and Ernst F: Towards X-ray free endovascular interventions-using HoloLens for on-line holographic visualisation. Healthc Technol Lett 4(5): 184-187, 2017. PMID: 29184662. DOI: 10.1049/htl.2017.0061

17 Frantz T, Jansen B, Duerinck J and Vandemeulebroucke J: Augmenting Microsoft's HoloLens with vuforia tracking for neuronavigation. Healthc Technol Lett 5(5): 221-225, 2018. PMID: 30464854. DOI: 10.1049/htl.2018.5079

18 Condino S, Carbone M, Piazza R, Ferrari M and Ferrari V: Perceptual limits of optical see-through visors for augmented reality guidance of manual tasks. IEEE Trans Biomed Eng 67(2): 411-419, 2020. PMID: 31059421. DOI: 10.1109/TBME.2019.2914517

19 Vassallo R, Rankin A, Chen E and Peters T: Hologram stability evaluation for Microsoft HoloLens. Medical Imaging 2017: Image Perception, Observer Performance, and Technology Assessment, 2018. DOI: 10.1117/12.2255831

Received April 18, 2021

Revised May 27, 2021

Accepted May 28, 2021 